\title{
Aspectos da argumentação e da recategorização metafórica no gênero sermão oral
}

\author{
Aspects of metaphorical recategorization and argumentation in the oral sermon genre
}

\author{
Max Silva Da Rocha* \\ Universidade Estadual de Alagoas \\ Palmeira dos Índios, Alagoas, Brasil \\ Maria Francisca Oliveira Santos** \\ Universidade Estadual de Alagoas \\ Arapiraca, Alagoas, Brasil
}

\begin{abstract}
Resumo: Os estudos da referenciação apresentam uma nova proposta teórica de analisar como um mesmo objeto de discurso (referente) é representado na mente dos interlocutores por meio de um texto. Essa representação é de ordem sociocognitiva e, por isso, requer um conhecimento de mecanismos cognitivos adquiridos e construídos nas relações sociais. Diante disso, esse trabalho objetiva realizar uma análise acerca da argumentação e da recategorização metafórica no gênero Sermão oral, procurando compreender como um mesmo referente, construto fundamental para a produção dos sentidos, evolui durante o texto oral. Por argumentação, compreendem-se as tentativas de convencer e persuadir o outro no plano das emoções; por recategorização, entende-se um contínuo processo cognitivo-discursivo de transformação dos referentes ao longo de um texto oral ou escrito; por Sermão oral, entende-se um discurso religioso, que tem como objetivo persuadir os ouvintes a respeito de uma determinada ideologia. O trabalho apoia-se nos pressupostos da Linguística Textual, numa vertente sociocognitivo-discursiva, que trata o texto como um processo de múltiplas faces. Por isso, embasa-se nos referenciais teóricos de Custódio Filho (2011, 2012, 2017), Cavalcante, Custódio Filho e Brito (2014), Fiorin (2017), Marcuschi (2008), Mondada e Dubois (1995), Koch (2004, 2017), Lima (2007), Silva (2013), entre outros. Para realizar as análises, optou-se por um Sermão oral, a fim de identificar os usos dos argumentos, além de verificar como um mesmo referente é apresentado e recategorizado metaforicamente durante a celebração religiosa cristã. O foco da análise é o domínio religioso cristão, mais precisamente, um Sermão oral, proferido por um informante de uma denominação cristã, localizada no agreste alagoano. As análises puderam evidenciar que um mesmo referente sofreu transformações ao decorrer da argumentação. Além disso, percebeu-se que a recategorização metafórica, enquanto construção dinâmica apresentou-se no plano do discurso de maneira crescente e decrescente para a construção do sentido.
\end{abstract}

Palavras-chave: Referenciação. Texto oral. Metáfora.

Abstract: The studies of the reference present a new theoretical proposal to analyze how the same object of discourse (referent) is represented in the mind of the interlocutors by means of a text. This representation is of a sociocognitive order and, therefore, requires a knowledge of cognitive mechanisms acquired and

*Mestrando em Letras e Linguística pelo Programa de Pós-Graduação em Letras e Linguística - PPGLL, da Universidade Federal de Alagoas - UFAL. Graduado em Letras/Português pela Universidade Estadual de Alagoas - UNEAL, campus III Palmeira dos Índios. E-mail: msrletras@gmail.com

${ }^{* *}$ Mestra e Doutora em Letras e Linguística pela Universidade Federal de Pernambuco - UFPE. Possui estágio de Pós-Doutoramento pela Universidade Federal da Bahia - UFBA. Professora do Programa de Pós-Graduação em Letras e Linguística da Universidade Federal de Alagoas - PPGLL/UFAL. Professora do departamento de Letras da Universidade Estadual de Alagoas - UNEAL, campus I Arapiraca. E-mail: linguagemeretorica@gmail.com. 
constructed in social relations. Therefore, this work aims at an analysis of metaphorical recategorization and argumentation in the oral sermon, trying to understand how the same referent, a fundamental construct for the production of the senses, evolves during the oral text. By argument, one understands the attempts to convince and persuade the other in the plane of the emotions; by recategorization, we mean a continuous cognitive-discursive process of transformation of referents throughout an oral or written text; by oral sermon, is meant a religious discourse, which aims to persuade listeners about a particular ideology. The work is based on the assumptions of Textual Linguistics, in a socio-cognitive-discursive, that treats the text as a process of multiple faces. Therefore, it is based on the theoretical references of Custódio Filho (2011, 2012, 2017), Cavalcante, Custódio Filho and Brito (2014), Fiorin (2017), Marcuschi (2008), Mondada and Dubois (1995), Koch , 2017), Lima (2007), Silva (2013), among others. In order to carry out the analyzes, an oral Sermon was chosen in order to identify the uses of the arguments, besides verifying how a same referent is metaphorically presented and recategorized during the Christian religious celebration. The focus of the analysis is the Christian religious domain, more precisely, an oral Sermon, delivered by an informant of a Christian denomination, located in the rural Alagoan. The analyzes could show that the same referent has undergone transformations during the course of the argument. Moreover, it was noticed that metaphoric recategorization, as a dynamic construction, appeared in the plane of discourse in an increasing and decreasing way for the construction of meaning.

Keywords: Referencing. Oral text. Metaphor.

\section{CONSIDERAÇÕES INICIAIS}

Este trabalho insere-se na linha dos estudos textuais, à luz de uma concepção sociocognitiva, a qual concebe a língua não como uma simples expressão do pensamento, nem como um mero instrumento de comunicação, mas sim como um lugar de interação entre os atores sociais. Nessa concepção de língua, tem-se o texto como um evento comunicativo dotado de aspectos sociais, cognitivos, culturais, entre outros, que fazem com que a produção de sentido aconteça de maneira negociada e organizada. Desse modo, esse trabalho toma como base analítica um texto religioso configurado num gênero, o Sermão oral, em que um informante, ocupando a posição de um líder/chefe religioso, profere um discurso persuasivo, procurando conquistar a adesão do seu auditório, entendido como os membros/fiéis da denominação religiosa.

A pregação proferida pelo informante é configurada num texto e este possui uma funcionalidade, que é o gênero; neste caso, o Sermão oral, que imbrica marcas provindas da oralidade como as pausas, as repetições, as entonações, além de outros aspectos que colaboram com a progressão textual do próprio sentido, além, é claro, dos referentes e/ou objetos de discurso, que vão sendo categorizados e recategorizados durante a pregação religiosa. Pelo fato de o Sermão ser um gênero oral, advoga-se que a oralidade, assim como a escrita, possui forma, estrutura, organização, planejamento e não pode ser vista de uma maneira dicotômica e/ou oposta, mas numa perspectiva de contínuo tipológico (MARCUSCHI, 2008), o qual considera as duas modalidades (escrita e oralidade) como sendo complementares.

Para a consecução desse estudo, escolheu-se o gênero discursivo Sermão oral como objeto por ser ele um gênero que, às vezes, é pouco estudado no espaço acadêmico e por ser um texto pertencente à modalidade de língua oral. Além do mais, destaca-se a relevante importância do citado gênero para o meio social, haja vista sua prática efetiva no Ocidente. Assim, o Sermão oral é entendido como um gênero de 
cunho predominantemente religioso, que tem como principal objetivo persuadir os ouvintes a respeito de uma determinada ideologia, por meio do discurso de autoridade (o líder religioso (ethos) ocupa essa função), ancorado em livros sagrados ou em dogmas religiosos e da oratória do religioso que o profere (SILVA, 2013).

Em se tratando da Argumentação, parte-se das postulações de Fiorin (2017), Reboul (2004) e Perelman e Olbrechts-Tyteca (2014), os quais entendem que a Argumentação trata de uma técnica discursiva que permite provocar ou aumentar a adesão dos espíritos a uma determinada proposição. Para Fiorin (2017, p.69), há diferenças entre argumento e argumentar; o primeiro diz respeito a um "enunciado que contribui para criar aceitação de outro enunciado (uma tese)"; o segundo significa "construir um discurso que tem a finalidade de persuadir". Assim, nesse estudo, entende-se a Argumentação como uma técnica de persuadir o outro no plano das ideias, das emoções. Observam-se apenas os argumentos que foram encadeados pelo líder religioso com fins persuasivos, sem adentrar profundamente nos estudos teorizados pela Nova Retórica.

Partindo da concepção sociocognitiva dos estudos da Linguística Textual, é possível analisar como acontece a interação entre os atores sociais do Sermão oral (líder religioso e membros/fiéis). Entende-se que a Argumentação se dá com a própria oralidade materializada na pregação do chefe religioso, fato que caracteriza os aspectos referenciais, os quais aparecem durante a própria proferição e vão sendo a todo tempo por ele (líder religioso) recategorizados. Essas retomadas dos referentes e/ou objetos de discurso caracterizam a Referenciação, entendida como "uma atividade de (re)elaboração do real e de se efetivar por meio de uma progressão recategorizadora, a referenciação é um processo resultante da negociação entre sujeitos [...]" (CUSTÓDIO FILHO, 2011, p.115).

A Referenciação ainda apresenta algumas especificidades capazes de proporcionar um olhar mais profundo no que respeita aos sentidos desencadeados pelos objetos de discurso. Custódio Filho (2017, p.65) apresenta três princípios básicos dos processos de Referenciação: a) o caráter sociocognitivo, que diz respeito às operações dinâmicas, sociocognitivamente motivadas, ou seja, um conhecimento social e cognitivamente compartilhado entre os sujeitos interativos, os quais, muitas vezes, retomam uma memória discursiva; b) a (re)elaboração da realidade, que trata das relações entre os atores sociais por meio das quais eles atuam conjuntamente para refratar a própria realidade, por meio de experiências vivenciadas/adquiridas; c) a negociação empreendida pelos interlocutores, que aborda a construção compartilhada dos interactantes, visto que sem acordo e sem negociação, não há diálogo e tampouco interação entre os sujeitos.

Assim, o presente trabalho fundamenta-se em analisar os aspectos provindos dos estudos da Argumentação e da Referenciação aplicados ao gênero discursivo Sermão oral, proferido em denominações religiosas cristãs do agreste alagoano. Para desenvolver a pesquisa, foi elaborada a seguinte pergunta norteadora: $O$ gênero Sermão oral apresenta marcas da Argumentação e da Recategorização Metafórica (manifestada ou não lexicalmente) para que seja efetivado enquanto gênero textual? Com o objetivo de 
responder à referida pergunta, fundamenta-se o interesse da pesquisa, além de analisar como a Referenciação acontece em contato com ações que ativam a memória discursiva dos interlocutores para a expressão das práticas verbais dos atores sociais.

\section{ACERCA DOS PROCESSOS REFERENCIAIS}

Esse estudo observa os aspectos referenciais no plano sociocognitivo, visto que os atores sociais reconhecem os referentes, manifestados ou não lexicalmente, como formas construídas no discurso, não sendo, dessa maneira, algo pronto, acabado. Para Lima (2007, p.80), a Referenciação diz respeito a uma abordagem processual da significação e, por ser um processo, é algo que vai sendo construído. Assim, entende-se a Referenciação como uma atividade discursiva, na qual convergem fatores perceptivocognitivos, a fim de atribuir significação aos mecanismos de produção do significado, aqui expresso, por um referente e/ou objeto de discurso (KOCH, 2017, p.61).

Os referente e/ou objetos de discurso “[...] são, por natureza, evolutivos, de modo que os usuários da língua, considerados como centro das atividades de designação, podem lançar mão de vários recursos para elaborar e fazer evoluir esses referentes" (LIMA, 2007, p.81). Os referentes são construídos à medida que o texto progride e, concomitantemente, têm-se as entidades estabelecidas no texto. No entanto, é importante frisar que os objetos de discurso podem aparecer tão somente no nível cognitivo, ou seja, sem menção lexical. Assim, é possível dizer que "os objetos de discurso, por seu turno, constituem-se por um conjunto de informações inclusas no saber compartilhado pelos interlocutores" (LIMA, 2007, p.81).

No gênero Sermão oral, é possível identificar referentes que aparecem categorizados e depois recategorizados durante o discurso. Por isso, algumas categorias da Referenciação são tomadas como recursos teórico-analíticos, como a introdução referencial, anáfora, dêixis, recategorização, dentre outras. A introdução referencial ocorre quando um referente novo é apresentado no texto, sem que nenhuma outra referência anterior tenha se referido a ele. "A ação de introduzir um referente no texto pode não ter o propósito apenas de colocar em cena uma entidade que passará por transformações, mas também de marcar um ponto de vista" (CAVALCANTE; CUSTÓDIO FILHO; BRITO, 2014, p.155). Nesse sentido, percebe-se que o objeto de discurso (tema do juízo) apresenta-se de forma diferente dos demais contextos em que é utilizado, pois é a primeira vez que ele aparece no texto. Veja-se o fragmento a seguir:

\section{Exemplo 1:}

L1 (...) então esse tema do juízo afunda muitas pessoas... aí na idade média onde as coisas se desenrolaram com a reforma... ali o pavor ao juízo era muito maior... a expectativa de vida ali era de quarenta anos...

A introdução referencial é posta logo no início do Sermão oral, quando o locutor diz "esse tema do juízo". Infere-se que há aí uma expressão nova que será retomada 
durante todo o texto oral. Tal expressão marca um ponto de vista do locutor, para que ele permaneça situado no tópico discursivo em questão. Assim, tudo o que for dito posteriormente vai, de algum modo, remeter a essa expressão introdutória.

A anáfora correferencial acontece quando um mesmo referente é retomado para dar continuidade ao sentido do texto, a progressão textual. Desse modo, "a anáfora reativa um referente, ou objeto de discurso, cuja interpretação é dependente de dados já introduzidos no texto" (CAVALCANTE; CUSTÓDIO FILHO; BRITO, 2014, p.155). Os atores sociais negociam o sentido e os aspectos sociocognitivos são ativados para que o sentido e a coerência sejam captados. O exemplo dois mostra como a anáfora consegue retomar o mesmo referente.

\section{Exemplo 2:}

... crianças morriam facilmente sem chegar à idade adulta... a igreja ela era unida ao Estado todo mundo que nascia já era batizada como criança porque se não não seria um cidadão...

Verifica-se que o informante faz uso de uma expressão anafórica correferencial direta por meio do referente "ela". Retoma-se o mesmo referente, neste caso, "igreja". Observa-se também que o referente está manifestado lexicalmente no texto e isso facilita a ativação do sentido. Mesmo assim, há uma necessidade de o interlocutor perceber a quem o objeto de discurso está se referindo. Não é uma forma etiquetada, mas algo que precisa ser visto a partir do contexto sociocognitivo, da negociação empreendida pelos atores sociais do evento comunicativo Sermão oral.

A dêixis diz respeito às expressões referenciais que marcam a fala do locutor seja no espaço, no tempo, no lugar etc. Ela se define "pela sua capacidade de criar um vínculo entre o cotexto e a situação enunciativa em que se encontram os participantes da comunicação" (CAVALCANTE; CUSTÓDIO FILHO; BRITO, 2014, p.85). Em referência à dêixis, destaca-se que ela se divide em pessoal, social, espacial, temporal, textual e dêixis de memória.

Destaca-se, neste trabalho, apenas a dêixis social e a espacial. A dêixis social diz respeito aos relacionamentos sociais entre os indivíduos, no que tange ao grau de formalidade. Desse modo, "a dêixis social também remete diretamente aos interlocutores [...] as estratégias de polidez dentro de uma determinada conjuntura sóciohistórica condicionam, assim, a escolha de títulos honoríficos e de outras expressões que manifestem a dêixis social" (CAVALCANTE; CUSTÓDIO FILHO; BRITO, 2014, p.88).

\section{Exemplo 3:}

...um dos pais da igreja conhecido Santo Agostinho disse que todas as coisas a igreja tinha cumPRIdo então eles não esperavam nada... 
No excerto, observa-se que o locutor chama Santo Agostinho de "um dos pais da igreja". Ao fazer isso, ele ratifica a escolha de títulos honoríficos, normas, polidez, atribuídas ao referido teólogo e filósofo da religiosidade Cristã. O leitor/ouvinte só aciona tal conhecimento, se conhecer parcial ou completamente quem foi Agostinho e qual sua importância para a Igreja Cristã. Assim, também, de algum modo, aparece a dêixis de memória, acionando a linha do tempo.

A dêixis espacial ocorre quando há uma marcação de "noções de proximidade/distância do locutor em relação a um dado referente. Eles apontam para um lugar situado referido com relação a quem fala" (CAVALCANTE; CUSTÓDIO FILHO; BRITO, 2014, p.90). O evento de fala também faz uma marcação de espaço em que situa a argumentação.

\section{Exemplo 4:}

... aí na idade média onde as coisas se desenrolaram com a reforma... ali o pavor ao juízo era muito maior...

Observa-se que o locutor define um espaço de onde ele fala, em relação ao discurso. Os ouvintes precisam recuperar, por meio de uma memória discursiva, os saberes de como foi o período da Idade Média. Caso não haja esse entendimento, a coerência ficará comprometida e a aceitabilidade do auditório não terá êxito. Desse modo, o informante retoma um espaço na linha do tempo, e o discurso remete a um tempo longínquo. Assim, a fala do enunciador (chefe religioso) ratifica um lugar definido e conhecido na história (período da Idade Média), além de situar a argumentação, caracterizando a categoria da dêixis espacial.

\section{RECATEGORIZAÇÃO: AS DUAS VERTENTES}

No que respeita aos estudos da Referenciação, é importante dizer que o presente estudo a tem como "uma estratégia textual-discursiva orientada por postulados de natureza sociocognitivista, interacionista e discursiva" (CUSTÓDIO FILHO, 2017, p.64). A importância dos estudos da Referenciação se dá porque essa categoria textual tornou-se uma possibilidade a mais de observar como os referentes são construídos e reconstruídos no interior dos textos orais e escritos. Além disso, os aspectos sociais e cognitivos ganharam maior destaque do que outrora. Ainda segundo Custódio Filho (2017), os processos referenciais se dão, muitas vezes, na mente dos sujeitos. Para o autor, não se pode negligenciar um olhar sociocognitivo para os estudos da Referenciação, já que é esse aspecto o fio condutor dessa categoria textual.

A mudança do nome Referência para Referenciação foi aplicada de forma coerente por Mondada e Dubois (1995), pois, a partir dessa mudança, ampliaram-se os estudos do fenômeno da Referenciação, visto que o primeiro nome reduzia o papel dos sujeitos e o contexto da própria enunciação. Além disso, os objetos de discurso eram considerados apenas objetos de mundo, como formas abstratas, não representando as 
atitudes, as intenções dos sujeitos. A partir da nova configuração da própria Referenciação, "os objetos de discurso, por seu turno, constituem-se por um conjunto de informações inclusas no saber compartilhado pelos interlocutores" (LIMA, 2007, p.81). Assim, observa-se que a Referenciação diz respeito a uma abordagem processual da significação.

Como já foi dito anteriormente, esse estudo evidencia o estudo da Recategorização, entendida como "um processo que se dá cognitivamente e que não se trata de um outro tipo de processo referencial, mas de algo que ajuda a constituir todas as retomadas anafóricas diretas, encapsuladas e indiretas" (CAVALCANTE; CUSTÓDIO FILHO; BRITO, 2014, p.99-100). Segundo Lima (2007), essa Recategorização se dá em duas vertentes. A primeira intitula-se recategorização metafórica manifestada lexicalmente; e a segunda denomina-se recategorização metafórica não manifestada lexicalmente.

A recategorização metafórica manifestada lexicalmente acontece por meio de uma retomada "total de um referente (anáfora direta correferencial), seguida de uma recategorização cognitiva, por metáfora, desse mesmo referente, a qual, por sua vez, aparece na superfície textual como um item lexical recategorizador explícito" (LIMA, 2007, p.90). Observa-se que o referente e/ou objeto de discurso é apresentado tanto no cotexto quanto no aspecto cognitivo dos envolvidos no discurso. Por isso, diz-se que "a recategorização lexical explícita consiste, basicamente, numa predicação de atributo sobre um objeto de discurso" (IBIDEM, 2007, p.82). Desse modo, há um referente que a todo o momento é retomado durante o texto, no entanto, ele recebe "novas" atribuições como, por exemplo, o sentido metafórico empreendido pelo sujeito enunciador.

A recategorização metafórica não manifestada lexicalmente ocorre quando um referente e/ou objeto de discurso não é manifestado por uma unidade lexical, mas aparece apenas na mente (processo cognitivo) dos atores sociais. Assim, as recategorizações metafóricas, manifestadas ou não, são de caráter cognitivo. Por esse motivo, não é difícil observar "[...] a existência de recategorizações metafóricas que se realizam apenas no nível cognitivo, exatamente as que estamos chamando recategorizações metafóricas não manifestadas lexicalmente” (IBIDEM, 2007, p.88). Nesse sentido, tem-se que a metáfora presente nesse tipo específico de recategorização situa-se na mente dos interlocutores. Isso ratifica o caráter sociocognitivo postulado pelos novos estudos em Linguística Textual.

Assim, a recategorização (manifestada ou não) observa como os referentes são construídos e reconstruídos durante a interação verbal, sabendo que "a forma como as pessoas representam um conceito altera-se em função do contexto em que é apresentado" (IBIDEM, 2007, p.78). É importante situar cada uma dessas categorias textuais, para que seja possível delimitar como serão aplicadas ao objeto desse estudo, o gênero Sermão oral.

Nesse sentido, procura-se entender como um mesmo referente e/ou objeto de discurso sofre alterações com ou sem menção lexical no texto. Além disso, Lima (2007) diz que a menção lexical vem acompanhada por uma metáfora; e também que a 
marcação do referente pode estar presente apenas no nível cognitivo. Assim, com essa nova proposta da autora, é possível "registrar a ocorrência de recategorizações metafóricas que se processam unicamente no nível cognitivo, não deixando nenhuma nova marca lexical explícita na superfície do texto" (IBIDEM, 2007, p.84-5). Essa proposta da citada autora fortalece os estudos provindos da Referenciação, contribuindo até com os estudos da Linguística Cognitiva, área esta que dialoga com os estudos textuais.

\section{A ANÁLISE DO GÊNERO SERMÃO ORAL}

Este trabalho está numa abordagem qualitativa, pois trabalha com as informações em processo e procura dar ênfase à qualidade ao invés da quantidade dos dados obtidos. Nesse sentido, a linha qualitativa "[...] explora as características dos indivíduos e cenários que não podem ser facilmente descritos numericamente. $O$ dado é frequentemente verbal e é coletado pela observação, descrição, gravação [...]” (MOREIRA; CALEFFE, 2008, p.73). Na pesquisa qualitativa, diferentemente da quantitativa, o que importa não é a quantidade e sim a qualidade dos dados; por isso, esse estudo segue uma linha processual, mão enfatizando o produto final.

O corpus foi colhido em denominações religiosas cristãs do agreste alagoano, e é composto por Sermões orais proferidos por líderes religiosos de tais denominações. Por motivos de extensão desse trabalho, escolheu-se um fragmento de um Sermão para ser analisado. Primeiramente, ocorreram as gravações das pregações; em um segundo momento ocorreram as transcrições (MARCUSCHI, 2003) dos dados orais; em um terceiro momento aplicou-se a teoria adotada; e, por fim, os resultados obtidos.

Esse estudo não leva em consideração os aspectos doutrinários, as crenças ou até mesmo a fé do informante e dos ouvintes. Volta-se tão somente à analisar dos processos de Argumentação e Recategorização no gênero Sermão oral, proferido em denominações religiosas cristãs do agreste alagoano.

O gênero discursivo Sermão oral é pertencente ao domínio discursivo religioso cristão e foi colhido durante uma celebração, tendo como tópico discursivo o dia do juízo. A duração do Sermão oral foi de vinte minutos, selecionado de um fragmento para ser analisado sob o enfoque das linhas de estudos aqui teorizadas. O auditório é composto por fiéis da denominação cristã, e o espaço da proferição é a própria denominação. Assim, há um propósito comunicativo na pregação do Sermão, que se explica pelo teor da mensagem, que foi o dia do juízo. O informante utiliza-se da oralidade (comunicação/linguagem verbal) para transmitir a mensagem a um auditório composto por fiéis da própria denominação, o que se verifica no fragmento a seguir:

(...) tudo necessário para que esse mundo pecaminoso continuasse ainda com um pouquinho de de vida... e aí então ele apresenta catástrofe catastrofismo ((incompreensível)) aí ele acrescenta e diz vai ser outra catástrofe e qual é?... o mundo destruído pelo fogo... have-rá juíZO:O juízo have-rá a condenação dos homens ímpios... (...) então esse tema do juízo afunda muitas pessoas... aí na idade média onde as coisas se desenrolaram com a reforma... ali 
o pavor ao juízo era muito maior... a expectativa de vida ali era de quarenta anos... crianças morriam facilmente sem chegar a idade adulta... a igreja ela era unida ao Estado todo mundo que nascia já era batizada como criança porque se não não seria um cidadão... um dos pais da igreja conhecido Santo Agostinho disse que todas as coisas a igreja tinha cumPRIdo então eles não esperavam nada...

Fonte: corpus da pesquisa 2018.

O Sermão apresenta um evento de fala em que o dia do juízo, envolvido com tudo aquilo que o circunda, é tratado de forma tenebrosa. Além disso, o informante busca, a todo o momento, causar uma emoção nos ouvintes. O referente e/ou objeto de discurso é caracterizado pela expressão lexical "dia do juízo". Por se tratar de um juízo, o referente desperta um conhecimento compartilhado entre os sujeitos, que é a escolha de alguns e a rejeição de outras, ou a condenação e a salvação.

Mais adiante, o informante utiliza a expressão "o mundo destruído pelo fogo". É possível observar que houve uma recategorização metafórica manifestada lexicalmente do referente "dia do juízo", visto que o mundo não é o mundo/planeta terra, mas as pessoas que nele residem. Assim, a expressão "o mundo destruído pelo fogo" também se associa ao dia do juízo, mas faz-se necessário o uso da metáfora como elemento argumentativo recategorizador.

Ao decorrer da proferição, o informante faz uso de outra expressão: “mundo pecaminoso". Novamente, verifica-se que a metáfora permanece presente, pois o mundo em si não realiza ações como, por exemplo, a de pecar. Por isso, infere-se que as pessoas são retratadas como o mundo. A recategorização metafórica manifestada lexicalmente ocorre mais uma vez, já que ainda se está falando acerca do dia do juízo. Mesmo que seja de forma indireta, os ouvintes, por meio do processo cognitivo, conseguem associar essa progressão recategorizadora.

Como fecho dos processos da recategorização metafórica manifestada lexicalmente, é possível identificar tal aspecto quando o enunciador fala que haverá a "condenação dos homens impios". Mais uma vez, verifica-se que a expressão utilizada recategoriza "o dia do juízo". Se for juízo, é necessário ter um julgamento e, consequentemente, uma condenação ou absolvição dos réus, estes representados por "bomens impios". Outro detalhe importante é que todas as expressões estão mencionadas no texto, mesmo que o ouvinte necessite acionar o processo cognitivo, não é difícil fazer tal associação entre os objetos de discurso que foram a todo o momento recategorizados por meio das metáforas.

Quanto à análise da recategorização, percebeu-se que um mesmo referente e/ou objeto de discurso (dia do juíro) sofreu transformações durante o texto oral e foi recategorizado metaforicamente de outras maneiras. Primeiramente ele apareceu como $o$ mundo destruido pelo fogo; em seguida foi reconstruído como o mundo pecaminoso; por fim, foi recategorizado como a condenação dos homens impios. Assim, ratifica-se o que Lima (2007) chama de recategorização metafórica manifestada lexicalmente, que consiste "basicamente, numa retomada total de um referente (anáfora direta correferencial), seguida de uma recategorização cognitiva, por metáfora” (LIMA, 2007, p.90). 
A argumentação também foi observada no presente estudo, haja vista o caráter argumentativo do gênero Sermão oral e porque "nas recategorizações lexicais explícitas, o subtipo argumentação, já definido anteriormente, tem natureza discursiva" (LIMA, 2007, p.83). Nesse sentido, em se tratando do uso dos argumentos, foi possível identificar que o informante utilizou pelo menos três argumentos: argumento do vínculo causal, argumento de autoridade e a interação entre o ato e a pessoa. Tais usos evidenciam o caráter persuasivo do citado gênero.

O primeiro argumento (vínculo causal) acontece quando o informante diz: “(...) todo mundo que nascia já era batizada como criança porque se não não seria um cidadão". Nesse sentido, o ato de ser batizado faz com que um sujeito seja ou não um cidadão. Assim, o batismo gera um vínculo que dá condições de ser um cidadão, motivo pelo qual era necessário ser batizado.

O segundo argumento (autoridade) aparece quando o enunciador encadeia a seguinte sequência discursiva: “(...) um dos pais da igreja conbecido Santo Agostinho disse que todas as coisas a igreja tinha cumPRIdo então eles não esperavam nada..." Observa-se que o informante recorre a um nome de prestígio, que é Santo Agostinho. Um nome de grande relevância para o domínio religioso cristão, pelo fato de o religioso ser um estudioso do cristianismo. Assim, o locutor sai de cena e passa a ocupar um lugar de portador do discurso de autoridade, não dele próprio, mas de Agostinho.

O terceiro e último argumento (interação entre ato e pessoa) aparece no seguinte trecho: "(...) então sempre se falava você tem que fazer as coisas direitinho porque o dia do juízo vai VIR e se você tiver em pecado você será destruído..." Esse último argumento mostra que as ações que os sujeitos realizam evidenciam quem eles são. Desse modo, fazer as coisas certas, de acordo com o ponto de vista religioso, faz com que determinado sujeito não sofra a "condenação". Além do mais, os atos revelam quem determinada pessoa é.

A análise dos aspectos provindos da Argumentação evidencia o caráter persuasivo do gênero Sermão oral. Além do mais, é possível afirmar que o gênero em estudo é argumentativo e visa à persuasão dos ouvintes, pois o chefe religioso se utiliza, a todo o momento, de técnicas argumentativas com fins persuasivos. Assim, acredita-se que os constructos teóricos da Linguística Textual e da Argumentação podem contribuir de maneira significativa para o estudo mais profundo do gênero Sermão oral, expandindose para outros gêneros do domínio religioso.

\section{CONSIDERAÇÕES FINAIS}

Para um maior aprofundamento desse estudo, que se utiliza de categorias da Argumentação e da Recategorização, é necessário cumprir alguns pontos importantes: a) observar outros gêneros orais e/ou escritos do domínio discursivo religioso, procurando descrever como acontecem tais processos referenciais nesses possíveis gêneros textuais; b) aprofundar os estudos em outros processos referenciais como, por exemplo, a dêixis; c) observar os referentes como objetos de discurso sociocogntivamente motivados; e d) ampliar os estudos em Argumentação, observando a tipologia argumentativa e a disposição dos argumentos. 
A partir desse trabalho, os estudos da Referenciação podem trilhar outros domínios discursivos, como foi mostrado com o domínio religioso, bem como uma possível contribuição, de algum modo, para os estudos dos gêneros orais argumentativos e persuasivos. Outro aspecto importante é a aplicação da Recategorização metafórica manifestada e não manifestada lexicalmente no gênero Sermão oral. Acredita-se que ainda não se têm trabalhos que tratem desse tema de forma exaustiva.

Assim, o presente trabalho tomou como ponto de partida os estudos de Lima (2007), no que respeita ao estudo da Recategorização em duas vertentes, em que a autora propõe algumas classificações para o fenômeno da Recategorização. Ainda, segundo a mesma autora, numa perspectiva sociocognitivista, esse processo se dá de forma dinâmica e de negociação entre os atores sociais. Além disso, buscou-se em Cavalcante, Custódio Filho e Brito (2014) a sustentação teórica dos estudos da Referenciação.

Acredita-se que a pesquisa conseguiu caminhar em direção ao objetivo do estudo, pois recorreu às duas linhas (Argumentação e Recategorização) como mecanismos teórico-metodológicos e aplicou as categorias elencadas no gênero em estudo. No entanto, as conclusões que foram alcançadas são provisórias, já que não há uma resposta definitiva. Por esses e outros motivos, é necessário realizar outras pesquisas no sentido de ampliar essa investigação no espaço religioso cristão.

Retornando à pergunta que norteou o trabalho: o gênero Sermão oral apresenta marcas da Argumentação e da Recategorização Metafórica (manifestada ou não lexicalmente) para que seja efetivado enquanto gênero textual? Verificou-se que os aspectos argumentativos e referenciais interagem entre si, permitindo que o Sermão oral aconteça de maneira negociada e organizada entre os atores sociais.

\section{REFERÊNCIAS BIBLIOGRÁFICAS}

CAVALCANTE, Mônica Magalhães; CUSTÓDIO FILHO, Valdinar; BRITO, Mariza Angélica Paiva. Coerência, referenciação e ensino. São Paulo: Cortez Editora, 2014.

CUSTÓDIO FILHO, Valdinar. Múltiplos fatores, distintas interações: esmiuçando o caráter heterogêneo da referenciação. 330p. Tese (Doutorado em Linguística) - Universidade Federal do Ceará, Fortaleza, 2011.

CUSTÓDIO FILHO, Valdinar. Rediscutindo o princípio de construção negociada dos objetos de discurso. Revista de Letras, Fortaleza/CE, v. 2, n.36, p.63-77, jul./dez. de 2017. FIORIN, José Luiz. Argumentação. São Paulo: Contexto, 2017.

$\mathrm{KOCH}$, Ingedore. Introdução à linguística textual. 2. ed. São Paulo: Contexto, 2017.

LIMA, S. M. C. Recategorização metafórica e humor: uma proposta classificatória. In: CAVALCANTE, M. M. et al. (Orgs.). Texto e discurso sob múltiplos olhares: referenciação e outros domínios discursivos. 2. ed. Rio de Janeiro: Lucerna, 2007. p. 74-103.

MARCUSCHI, Luiz Antônio. Análise da Conversação. 5. ed. São Paulo: Editora Ática, 2003. 
MARCUSCHI, Luiz Antônio. Produção textual, análise de gêneros e compreensão. São Paulo: Parábola Editorial, 2008.

MONDADA, Lorenza; DUBOIS, Danièle. Construction des objets de discours et categorisation: une approche des processus de référenciation. In: BERRENDONNER, A. e M-J REICHLERBEGUELIN (eds). 1995, pp. 273-302.

MOREIRA, H. CALEFFE. L. G. Metodologia da pesquisa para o professor pesquisador. 2. ed. São Paulo: DP\&A, 2008.

PERELMAN, Chain, OLBRECHTS-TYTECA, Lucie. Tratado da argumentação: a nova retórica. 3. ed. São Paulo: Martins Fontes, 2014.

SILVA, Lucas Nascimento. O orador Jesus Cristo e suas técnicas argumentativas: um estudo retórico no Sermão do Monte. Dissertação de Mestrado. Universidade do Estado da Bahia. Departamento de Ciências Humanas. Orientador: Gilberto N. Telles Sobral. Salvador, 2013.

REBOUL, Olivier. Introdução à retórica. São Paulo: Martins Fontes, 2004.

ROCHA, Max Silva da; SANTOS, Maria Francisca Oliveira. Análise retórica do gênero discursivo sermão oral. Polifonia, Cuiabá/MT, v. 25, n.37.1, p.88-106, jan./abr. de 2018.

Recebido em: 05/06/2018

Aprovado em: 23/07/2018

Publicado em: 31/12/2018 